\title{
A QUÍMICA MEDICINAL NA PRÓXIMA DÉCADA
}

\author{
Carlos A. Montanari \\ Departamento de Química - ICEx/UFMG - Campus da Pampulha - 31270-901 - Belo Horizonte - MG
}

Recebido em 22/1/99; aceito em 27/7/99

\begin{abstract}
BRAZILIAN MEDICINAL CHEMISTRY IN THE NEXT DECADE. Medicinal chemistry is multi, trans and inter disciplinary on its essence. It has a great deal of challenging Brazilian chemists in the next decade. The pharmacy school is essentially attached and has an important role in the development on the field that is still in domain of big pharmaceutical industries. This work shows the challenges to face and directions to jointly follow for a myriad of researchers throughout the country. The unnamed science has to work out through specific objectives in order to diminish the problems associated with human being health. A brief history is presented where the main goal is to devise chemistry, as a natural science, and many other interfaced disciplines.
\end{abstract}

Keywords: iatrochemistry; biorreceptors; computer-aided molecular design.

\section{INTRODUÇÃO}

As épocas de transição, por exemplo o final de milênio próximo, trazem drásticas modificações das mais diversas características. Quando elas não ocorrem de forma materializada, ocorrem de forma mística, na mente dos seres humanos. Em tempos de modernidade, a sociedade contemporânea precisa estar apta a adaptar-se aos novos desafios e a eles enfrentar de forma contundente. Somente assim, avanços ocorrerão.

O Brasil vive neste final de milênio, um dilema sem precedentes. As dificuldades sociais lado-a-lado com as necessidades tecnológicas, apenas para citar duas, apresentam-se como uma dicotomia extemporânea que ainda está viva em todos(as) aqueles(as) que pensam grande. Mas, em realidade as transformações globalizadas do mundo contemporâneo estão tornando a sociedade mais competitiva, mais interessada em solucionar problemas, em melhorar as condições sociais e etc. Na área de saúde essa situação faz-se, per se, inconfundivelmente prioritária, nas suas mais diversas frentes. Não importa a área de pesquisa, seu grau de aceitação ou seja lá o que for. O que importa é que os cientistas brasileiros estão mais conscientes do papel que têm a desempenhar na história do país.

Nesse sentido, a química medicinal inclui-se como um grande desafio para os pesquisadores desejosos de contribuir para o avanço dessa área multi-, trans- e interdisciplinar e, obviamente, constitui um grande desafio ${ }^{1}$.

Neste final de milênio faz-se mister conclamar os cientistas brasileiros, para a importância do trabalho conjunto em uma ciência sem nome, como a química medicinal.

Este trabalho visa a busca de uma redefinição da disciplina de química medicinal, sua proposta e seu significado. Se algo for considerado óbvio, por certo não será insignificante dizer. Talvez, não tenhamos tido ainda a oportunidade de deixar o óbvio no passado. A minha expectativa, em nome da Divisão de Química Medicinal da Sociedade Brasileira de Química é que esse passado vire prólogo 2 .

\section{UM POUCO DE HISTÓRIA ${ }^{3-5}$}

A química medicinal tem-se desenvolvido e alcançado sucesso nos tempos modernos, mas suas origens remontam à antiguidade mais longínqua.

montana@dedalus.lcc.ufmg.br, http://www.qui.ufmg.br/ nequim
A ciência médica moderna tem suas origens fundamentadas essencialmente na Grécia. No começo, a ciência médica tinha um caráter puramente evocativo do espirito. Apolo é considerado o fundador da ciência médica e, em tempos pós-homéricos, seu filho Esculápio, (em Homero, o príncipe de Tessália) considera que a saúde do ser humano pode ser restaurada através da "cura oracular".

Esse tipo de medicina, entretanto, já continha fundamentos racionais. Os sacerdotes, responsáveis por preces curativas, interpretavam os sonhos de peregrinos e prescreviam dietas com base nessas interpretações. Os templos tornaram-se escriturados com receitas devotadas ao Deus, que serviam como base para identificação de doenças semelhantes e, consequentemente, uso em futuras prescrições. Paralelamente, surgiram os primeiros médicos que se organizaram em corporações ou associações. Isso, entretanto, causou uma ruptura com o tratamento espiritual tradicionalmente atribuído aos descendentes do Deus Esculápio. Os registros encontrados em Homero mostram que esses médicos faziam uso de vegetais de origem egípcia marcando, assim, a influência do país dos Faraós sobre a medicina grega. As primeiras escolas de medicina surgiram no norte da África. Entretanto, uma das mais antigas escolas de medicina foi criada próxima ao santuário de Esculápio, na ilha de Cós, onde nasceu o homem que primeiro pôs a medicina em bases científicas. Seu nome, hoje conhecido de todos os médicos: Hipócrates, "o Divino".

A primeira regra estabelecida por Hipócrates foi a observação individualizada da pessoa. Estabeleceu-se, então, um paradigma de fundamental importância até os nossos dias que estabelece a experiência pessoal e a consulta aos escritos prévios, como formas do conceito de "colecionar" informações, agrupando-as para servirem como base de novos diagnósticos.

Hipócrates estabeleceu a ciência médica do ponto de vista puramente empírico.

Um salto para o século XVI, enfatiza a fase totalmente empírica da medicina. Paracelso, em sua primeira aparição pública, queimou os trabalhos de Galeno e deu tributos apenas aos "Aforismos" de Hipócrates. Esse comportamento exasperado, característico de Paracelso, tenta demonstrar um certo radicalismo ao estabelecer que suas idéias, prevalecentes sobre dogmas pré-estabelecidos, têm o objetivo de exultar a necessidade em modificar-se o pensamento galênico. A teoria de Galeno, que estabelecia ser a doença baseada em quatro humores - o sangue, a urina, a bile e a atrabile, não tinha qualquer significado científico. Isso provocou um retardamento por muito 
tempo da evolução científica na medicina. E, foi exatamente contra isso que Paracelso manifestou-se publica e ardorosamente!

Paracelso foi considerado como um flamejante meteoro que aparece e desaparece muito rapidamente. Trazia consigo, entretanto, um desejo compulsivo de destruir o "velho". Afora seus impulsos filosóficos, Paracelso revolucionou o conceito de medicina prática quando estabeleceu que cada doença tinha sua própria etiologia. Estabeleceu, com isso, o uso de substâncias químicas com finalidade terapêutica e a importância de águas minerais e drogas de origem vegetal. Ele imaginava que o tratamento de cada doença dar-se-ia com o uso exclusivo de um determinado medicamento (um pensamento reducionista que ainda opera, até certo grau, em nossos dias).

Paracelso pode ser considerado o fundador da química medicinal (sob a forma da iatroquímica) porque ele considerava que a descoberta dessas substâncias químicas se constituiria num dos principais objetivos da arte médica. Seus pensamentos eram tão arraigados que ele nomeava as doenças de acordo com os remédios que usava, já que as artes médicas não emanavam do espírito de Deus, mas sim da imaginação humana.

No entanto, a farmácia foi um dos ramos mais negligenciados da medicina ocidental, ao contrário do que ocorria entre os árabes. Além das drogas "simples" também existiam as "compostas". Estas últimas, entretanto, eram (talvez continuem sendo!) motivo de muitas controvérsias e erros: autores individuais forneciam diferentes composições para o mesmo medicamento; sob o mesmo nome outros autores entendiam composições completamente diferentes. Um problema que, de certa forma, ainda persiste em nossos dias quando são tratados os medicamentos genéricos e fantasiosos.

A química também foi cultivada na Alexandria, nos séculos XVI e XVII ${ }^{6}$, onde o conhecimento empírico advindo do Egito antigo floresceu com os pensamentos Gregos que ajudaram a torná-la mais científica. Mas a influência do Neo-Platonismo fez dos químicos alexandrinos, místicos. A busca de substâncias como a "pedra filosofal" que seria capaz de converter metais comuns em preciosos, o "elixir da vida" que curaria todas as doenças da vida mortal. A Idade Média estava especialmente interessada neste tipo de alquimia, embora também tenham dado contribuição empírica para a química.

Com o objetivo de colocar uma certa ordem nessa confusão, foi publicada, em 1498, em Florença, aquilo que pode ser chamado de a primeira farmacopéia (Riceptario). Assim, os boticários puderam manipular suas fórmulas compostas sem muitos enganos.

Muito tempo depois, já no século XVII, os farmacêuticos que preparavam as drogas iatroquímicas mantinham uma estreita prática de laboratório mais segura do que os médicos iatroquímicos. Por força disso, os farmacêuticos tinham conhecimentos mais profundos da natureza dos materiais que eram usados. Graças a isso, as novas descobertas demandavam melhores explicações do que aquelas que eram oferecidas pelas forças místicas e ocultas. Um desenvolvimento revolucionário acabou levando às idéias da química moderna.

No século XIX o desenvolvimento da química orgânica, sobretudo na Alemanha, levou à descoberta de muitos medicamentos sintéticos como por exemplo, a aspirina.

A história da aspirina pode ser buscada em tempos egípcios remotos quando os extratos de casca de salgueiro eram usados no tratamento da inflamação. O princípio ativo foi identificado como sendo um glicosídio do álcool salicílico. Os efeitos colaterais dos sais sódicos do salicilato sugeriram estudos de derivados e a síntese de compostos orto-acetilados foi realizada. Assim, o ácido acetil-salicílico foi sintetizado em 1899, para o tratamento de febre e reumatismo. Foi comercializado pela Bayer com o nome de aspirina.

Durante a Idade Média e Antiga, a pratica do cultivo de plantas medicinais em jardins especiais já constituía uma preocupação das ciências biológicas ${ }^{7}$. Jardins dessa natureza existi- ram em Salerno e Veneza no século XIV. O principal objetivo desses jardins era a dedicação à arte da cura, portanto não eram apenas jardins botânicos. Somente em meados do século XVI é que as universidades passaram a estudar a botânica como um ramo da ciência distinta da arte da medicina.

\section{TRANS-, MULTI- E INTERDISCIPLINARIDADE}

Em primeiro lugar há a necessidade do reconhecimento de que a química medicinal é uma disciplina híbrida que está no centro de um grande espaço inter- e multidisciplinar constituído, por exemplo, por: biofísica, biologia molecular, bioquímica, clínica médica, físico-química, fisiologia, neurobiologia, patologia, química biológica, química inorgânica, química orgânica e química quântica.

Esse formalismo não leva, necessariamente, ao domínio da química medicinal sobre as outras disciplinas. Talvez seja difícil para o nosso sistema ainda compartimentalizado compreender, mas todas essas disciplinas funcionam conjuntamente dentro do aspecto trans-(sobre a inserção de um conceito em outro), multi- (sobre a co-existência de múltiplos) e interdisciplinar (sobre a necessidade de interfaces), onde todas as partes são fundamentais e, a eventual falha de uma delas, prejudica todo o sistema! Isso talvez seja assim porque a atribuição do prêmio Nobel, em 1987, a Cram, Lehn e Pedersen, que estabeleceram as bases dos processos de reconhecimento molecular (a química supramolecular), implícitas às interações droga-receptor, ocorreu através da fundamentação intrínseca (latente) à química medicinal.

\section{PLANEJAMENTO MOLECULAR BASEADO EM COMPUTADOR ${ }^{8,9}$}

Nas últimas duas décadas a arte da descoberta e desenvolvimento de novas entidades químicas mudou drasticamente com a introdução de novos métodos em química analítica. A química analítica revolucionou a análise de compostos químicos e o estudo de processos biológicos. A cristalografia e a RMN contribuem de maneira significativa para a pesquisa estrutural, revelando detalhes sobre a estrutura e função de macromoléculas, tais como ácidos nucléicos e proteínas.

A segunda revolução, desenvolvida em paralelo e que agora tornou-se indispensável, relaciona-se com o uso de computadores no planejamento, descoberta, elucidação de processos químicos e biológicos através da estrutura tridimensional de pequenas e macromoléculas. Associados aos métodos de modelagem molecular, os métodos estatísticos conhecidos como quimiométricos são amplamente usados em química analítica e também em processos quantitativos do planejamento molecular.

O uso de descritores físico-químicos em correlações entre estrutura e propriedade, SPC, estão hoje embasados em informações tridimensionais que codificam a conformação molecu$\operatorname{lar}^{10}$, e os planejamentos estatísticos ${ }^{11,12}$, acessíveis através dos métodos computacionais.

Os computadores podem ser usados no planejamento molecular em uma das seguintes situações: (i) sistemas de informação química ${ }^{13}$; (ii) química computacional; (iii) química combinatória, diversidade molecular, similaridade molecular ${ }^{14}$; (iii) planejamento de novo; (iv) modelagem molecular; (v) geração farmacofórica; (vi) predição de propriedades; (vii) correlações estrutura-propriedade, QSAR 2D; (viii) QSAR 3D(4D), CoMFA, GRID, GOLPE; (ix) planejamento de síntese, banco de dados em reações químicas, etc...

A química computacional envolvida nesse contexto pode ser considerada equivalente ao planejamento molecular baseado em computador, CAMD.

A importância do entendimento dos mecanismos moleculares através das simulações químicas, no entendimento de processos químicos e biológicos pode ser enfatizada através da seguinte sentença: ${ }^{15}$ 
"O rápido crescimento de nosso entendimento mecanístico sobre processos químicos e biológicos combinados com o desenvolvimento da biologia molecular, tem mostrado que os processos modulatórios essenciais e o modo pelo qual eles são alterados pelos fatores ambientais, podem ser entendidos ao nível molecular. Para que isto seja verdadeiro, informações detalhadas, ao nível da resolução atômica, sobre as estruturas e propriedades das moléculas-chave envolvidas precisam ser conhecidas. As informações estruturais podem ser obtidas de métodos experimentais como cristalografia de raios-X e RMN multidimensional, mas estes métodos ainda são caros e são necessários longos períodos de estudo. Os aspectos teóricos da físico-química, utilizando simulações computacionais dos mecanismos moleculares, corroboram os experimentos e, em muitos casos, fornecem informações alternativas. Complementando a teoria formal e a experimentação direta, e, apoiando-se em inferências inerentes à biologia molecular e à biologia estrutural, as simulações computacionais de sistemas químicos e biológicos tornaram-se um fator principal na pesquisa moderna.'

O principal objetivo é a racionalização dos mecanismos de reação e ação observados, na tentativa de encontrar hipóteses para esses mecanismos e planejar novas estruturas moleculares com propriedades mais específicas. Desse modo, o planejamento molecular baseado em computador pode não apenas descrever o resultado experimental, como também explicá-lo e fornecer subsídios para testá-los antes do experimento direto.

Quatro aspectos básicos poderiam ser delineados para o entendimento da situação atual:

1. No início as descobertas foram naturais. No Brasil, a química medicinal natural precisa ser redescoberta por nossos químicos medicinais.

2. Quando Fraser e Brown propuseram, em 1869, uma definição de relações entre estrutura-química e atividade eles, na realidade, estabeleceram o exemplo pioneiro da colaboração entre farmacologistas e químicos. Existem vários exemplos dessa colaboração no Brasil mas, certamente, ela ainda está muito distante da proposta de Fraser e Brown.

3. A química sintética continua sendo uma arte preocupante ${ }^{16}$. Preocupante porque é através dela que se materializará, em muitos aspectos, a química medicinal. O que os químicos sintéticos precisam compreender é que a síntese de compostos potencialmente ativos contra algum alvo biológico, tem de ser baseada na estrutura derivada de estudos cristalográficos e RMN associados aos métodos computacionais ${ }^{17}$. Há pouca dúvida de que no futuro esses procedimentos de racionalização do planejamento de drogas serão muito importantes neste país.

Não obstante, nessa questão está diretamente implícito o fato de que a estrutura alvo do sistema biológico é conhecida e sua utilização no planejamento baseado em uma descrição tridimensional é factível. Entretanto, já é comum o emprego de bancos de moléculas contendo números que estão fora da prática rotineira e precisam ser incluídos no processo de dinâmica molecular por aproximação ou racionalizados em termos de suas reais dissimilaridades moleculares ${ }^{18}$. Além disso, a síntese combinatória tem contribuído para o aumento da diversidade química que através do ensaio randômico de alta eficiência, HTS, com moléculas de similaridade estrutural desconhecida tem apresentado excelentes resultados na busca de novos ligantes ${ }^{19,20}$. A química combinatória representa o avanço recente mais importante da química medicinal ${ }^{21}$.

4. O ensaio biológico ainda é um desafio a ser vencido. Ambos, o ensaio em batelada e o mecanístico precisam ser realizados em larga escala e com rapidez.

\section{ENTÃO, O FUTURO}

Parece óbvio e crucial que a seleção de um determinado objetivo terapêutico e então seu alvo farmacológico que corresponderá a uma necessidade médica real continuarão constituindo árduas tarefas ${ }^{22}$, incluindo novos métodos onde a química medicinal também terá papel fundamental a desempenhar, como já é o caso dos mecanismos antisenso ${ }^{23,24}$. Algumas áreas como o diabetes, osteoporose, AIDS, osteoartrite, doença de Alzheimer, doenças cardiovasculares e muitas formas de câncer, precisarão de terapias mais eficazes. Então essas áreas podem ser consideradas prioritárias (se é que se pode falar em prioridades quando se trata da saúde humana!) para as pesquisas. Não obstante, é preciso ressaltar que outras doenças emergentes ou então aquelas que retornam como multirresistentes também constituirão problemas a resolver.

Por outro lato, a medicina e a química medicinal que estão sendo transformadas pela biologia molecular conterão, certamente, novos objetivos. Quando o projeto do genoma humano estiver completado ele irá, pelo menos em tese, definir os alvos do século XXI! ${ }^{25,26}$. Questões éticas, entretanto, serão muito importantes aqui e a química medicinal não ficará fora dessa discussão.

No Brasil, as questões a responder podem ser: quantos e quais projetos serão realizados? A academia continuará sendo a única vetora, ou a indústria nacional irá participar desse processo conjunta ou individualmente? Os objetivos continuarão sendo estabelecidos por força do mercado? Precisamos de uma "mega"-indústria ou "pequenos" e diversos centros trabalhando em colaboração poderão estabelecer e realizar as pesquisas mais realisticamente?

Novos alvos celulares precisarão ser estabelecidos e novos métodos de ensaio também. A falta do ensaio em batelada ainda é uma falha importante e graças a isso muitas substâncias continuam "engavetadas". Além disso, o Brasil também precisará contribuir para os novos alvos e estudar mecanismos de ação daqueles que são de interesse para as nossas terapias, principalmente em doenças tropicais ${ }^{27}$.

Os estudos de QSAR/QSPR em ciências do ambiente ainda estão tímidos. Esse método vem sendo usado por autoridades, indústrias e outras instituições na avaliação dos riscos que substâncias químicas causam ao meio ambiente. Talvez a principal razão para isto seja o fato de que qualquer teste biológico, por mais básico que ele seja, demorará décadas para ser realizado. Dessa forma, com o intuito de se estabelecerem prioridades, modelos QSAR/QSPR preditivos são de fundamental importância. Estes modelos poderão conduzir ao planejamento racional de compostos sem efeitos laterais indesejados, pela otimização de suas propriedades ambientais relevantes ${ }^{28}$.

A microcalorimetria biológica ${ }^{29}$ parece ser um método capaz de realizar ambos os estudos: os de análise em batelada (HTS) e aqueles mecanísticos. O investimento inicial é elevado, mas sua manutenção nem tanto ${ }^{30}$. Além disso, quando diluído entre inúmeros pesquisadores no Brasil os custos significarão quase nada! Os resultados são excelentes.

A interação do químico medicinal com o farmacologista é crítica na obtenção desse sucesso e constituirá, ainda, uma questão a ser resolvida. Entretanto, como a biologia molecular propiciará incontáveis novos alvos, suas características fisiológicas ou patológicas precisarão ser definidas. A química medicinal tornou-se o "gargalo-cinético" nos processos de descobrimento de drogas, e novas tecnologias aumentarão e melhorarão os processos de refinamento. Embora os químicos medicinais sejam capazes de otimizar compostos matrizes muito rapidamente no que concerne à potência, melhorar a cinética, metabolismo e propriedades toxicológicas ainda constituem uma difícil tarefa ${ }^{31}$ que terá de ser enfrentada nos processos de interação e integração já iluminados em nossos pensamento.

A tríade química combinatória-HTS-planejamento molecular continuará sendo muito poderosa na descoberta e desenvolvimento de novas entidades químicas, mas não poderá padecer do poder inventivo de um químico medicinal bem treinado e, 
principalmente, acompanhado de um farmacologista imaginativo. A química combinatória tem seu principal impacto na descoberta da substância matriz, cuja estimativa de tempo pode estar reduzida a $18-24$ meses $^{32}$ na primeira fase do processo. A segunda fase, a de otimização poderá envolver as fases préclínica e clínica e, nesse caso, é óbvio, as estimativas temporais preliminares continuam válidas.

Não obstante as conjecturas acima sejam válidas em um mundo globalizado, parece evidente que em nosso caso outras preocupações de caráter formativo ainda permearão nossas salas de aula ${ }^{33-36}$.

\section{AGRADECIMENTOS}

O autor deseja expressar profundo agradecimento ao Prof. Carlos Alberto Filgueiras, vorazmente motivador dos estudos que permeiam o conhecimento necessário para o engrandecimento não só da ciência de um modo geral mas, principalmente, de sua escorreita aplicação e utilização em nosso país. Ao Prof. Luiz Carlos Gomide de Freitas, primeiro responsável pela existência deste manuscrito. Ao Prof. Ricardo Bicca Alencastro por seu encorajamento. Ao assessor 1, que revisou o texto e apontou importantes aspectos de sua natureza intrínseca. Ao CNPq, CAPES, FAPEMIG, FINEP, que estão financiando os projetos de pesquisa do NEQUIM.

\section{REFERÊNCIAS}

1. Montanari, C. A.; Presença Pedagógica 1998, 4, 88

2. "What's past is prologue". Shakespeare, W.; The Tempest

3. Leicester, H. M.; The Historical Background of Chemistry. Dover Publications, Inc., New York, 1956

4. Jacobi, J., Paracelsys. Selected Writings, Princeton University Press, New Jersey, 1988

5. Debus, A. G.; A longa revolução Química, Ciência Hoje 1991, 13, 34

6. Wolf, A. em History of Science, Jarrold and Sons Ltd., London, 1950, p.7

7. Wolf, A. em History of Science, Jarrold and Sons Ltd., London, 1950 , p.395

8. Triggle, D. J.; The Future of Medicinal Chemistry, em "Perspectives in Medicinal Chemistry", Eds. Testa, B., Kyburz, E. Fuhrer, W e Giger, R.; VCH, Weinheim, 1993, 1

9. Vanhoutte, P. M.; Medicinal Chemistry. The Challenges for the Future, em "Computer-Assisted Lead Finding and Optimization. Current Tools for Medicinal Chemistry", Eds. Van de Waterbeemd, Testa, B. e Folkers, G., WileyVCH, Weihnheim, 1997, 3

10. Barreiro, E. J.; Rodrigues, C. R.; Albuquerque, M. G.; deSantAnna, C. M. R.; Alencastro, R. B.; Quim. Nova 1997, 20, 300
11. Mager, P. P.; Med. Res. Ver. 1997, 17, 453

12. Mager, P. P.; Med. Res. Ver. 1997, 17, 505

13. Russo, M.; Santagati, N. A.; LoPinto, E.; Information Sciences 1998, 105, 299

14. Bures, M. G.; Martin, Y. C.; Cur. Opinion Chem. Biol. 1998, 2, 376

15. Weinstein, H.; Computational Simulations of Molecular Structure, Dynamics and Signal Transduction in Biological Systems: Mechanistic Implications for Ecological Physical Chemistry. Em: Trends in Ecological Physical Chemistry. Bonati, L.; Cosentino, U.; Lasagni, M.; Moro, G.; Pitea, D. e Schiradi, A. (eds.). Elsevier Science Pub., Amsterdam, 1996, p. 1-16

16. Terashima, S.; Yakugaku Zasshi-Journal Of The Pharmaceutical Society Of Japan 1998, 118, 353

17. Martin, J. L.; Cur. Med. Chem. 1996, 3, 419

18. Cummins, D. J.; Andrews, C. W.; Bentley, J. A.; Cory, M.; J. Chem. Inf. Comp. Sci. 1996, 36, 750

19. Williard, X.; Pop, I.; Bourel, L.; Horvath, D.; Baudelle, R.; Melnyk, P.; Deprez, B.; Tartar, A.; Eur. J. Med. Chem. 1996, 31, 87

20. Gordon, E. M.; Gallop, M. A.; Patel, D. V.; Acc. Chem. Res. 1996, 29, 144

21. Lam, K. S.; Anti-Cancer Drug Des. 1997, 12, 145

22. Recanatini, M.; Farmaco 1996, 51, 5

23. Crooke, S. T.; Bennett, C. F.; Ann. Ver. Pharmacol. Toxicol. 1996, 36, 107

24. Boral, A. L.; Dessain, S.; Chabner, B. A.; Cancer Chemother. Pharmacol. 1998, 42, 3

25. Metcalf, B. W.; Pure App. Chem. 1998, 70, 359

26. Wiley, S. R.; Cur. Pharm. Des. 1998, 4, 417

27. Li, R. S.; Chen, X. W.; Gong, B. Q.; Selzer, P. M.; Li, Z.; Davidson, E.; Kurzban, G.; Miller, R. E.; Nuzum, E. O.; McKerrow, J. H.; Fletterick, R. J.; Gillmor, S. A.; Craik, C. S.; Kuntz, I. D.; Cohen, F. E.; Kenyon, G. L.; Bioorg. Med. Chem. 1996, 4, 1421

28. Eriksson, L.; Johansson, E.; Müller, M. and Wold, S.; Quant. Struct.-Act. Relat. 1997, 16, 383, e referências citadas

29. Montanari, C. A.; Montanari, M. L. C.; Beezer, A. E. e Giesbrecht, A. M.; Quím. Nova 1993, 16, 133

30. Montanari, C. A.; Quím. Nova 1995, 18, 56

31. Wess, G.; Drug Discovery Today 1996, 1, 529

32. Kuhlmann, J.; Int. J. Clin. Pharmacol. Ther. 1997, 35, 541

33. Monge, A.; Quim. Nova 1997, 20, 683

34. Ruenitz, P. C.; Am. J. Pharm. Ed. 1997, 61, 302

35. Ganellin, C. R.; Mitscher, L. A.; Topliss, J. G.; Med. Res. Rev. 1998, 18, 121

36. Monge, A.; Ganellin, C. R.; Ide, J.; Koga, N.; Lindberg, P.; Mitscher, L. A.; Muller, J. C.; Perun. T. J.; Topliss, J. G.; Wermuth, C. G.; Bull. Chem. Soc. Ethiopia 1997, 11,163 